\title{
Comparison of the Infertility-Related Stress Among Couples and its Relationship With Infertility Factors
}

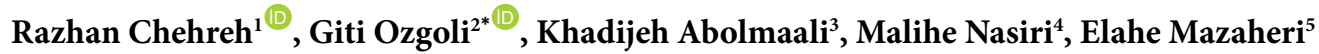

\begin{abstract}
Objectives: Inability to have a child is stressful and affects all aspects of couples' lives. Infertility diagnosis, duration and reason of infertility, treatment failure, and frequent pregnancy tests are among the stress-inducing factors in couples. The current study aimed to compare infertility-related stress among couples and evaluate its relationships with infertility factors.

Materials and Methods: This cross-sectional study was performed on 150 infertile couples (300 individuals) visiting infertility centers of Tehran. The data were collected using the Fertility Problem Inventory (FPI) and fertility and demographic characteristics form. The subjects were selected through convenience sampling method. The data were analyzed through inferential statistics, including paired samples t-test, independent samples $t$ test, ANOVA, and linear regression.

Results: According to the results, the mean stress score of women was significantly higher than that of the men $(P=0.007)$. There was a significant difference between males and females regarding the mean scores of social concern and need for parenthood $(P=0.005)$. The mean score of infertility-related stress was also significantly higher in women with treatment failure than in men $(P=0.01)$. Conclusions: Based on the findings of the present study, infertile women experienced greater stress than males. Furthermore, infertility-related stress increased in women due to treatment failure. Therefore, it is recommended that women who have experienced treatment failure be subjected to precise psychological evaluations before undergoing the treatment process.

Keywords: Couples, Infertility, Stress, Treatment failure
\end{abstract}

\section{Introduction}

In many cultures, the capability to be a parent is the basic condition for personal accomplishment, social acceptance, and fulfillment of sexual identity (1). Accordingly, it seems logical to suppose that the inability to have a child can cause tension and affect all aspects of couples' lives (24). Infertility refers to a condition in which couples cannot achieve pregnancy after 12 months of regular sexual intercourse without any prevention methods (5).

This phenomenon is an important public health issue and a vital event in marital life, which affects $10 \%-15 \%$ of couples throughout the world (6). Infertility as a stressful multidimensional phenomenon leads to emotional imbalance, anxiety, stress, and depression (7-9). Luk et al indicated that approximately $36 \%$ of the infertile women had higher depression scores than their fertile counterparts (10). Patel et al also reported that the prevalence of stress among infertile women was $80 \%$ (11).

Infertility diagnosis and the treatment failures are sudden, unexpected, and frightening crisis that can affect the adaptation process of couples. In addition, mental pressure, loneliness, disappointment, and loss of control are highly observed in people referring for assisted reproductive methods $(11,12)$. Studies have shown that such factors as age at the time of infertility diagnosis, infertility duration, marriage duration, cause of infertility, treatment failure, frequent pregnancy tests, and more importantly social stigma lead to the creation of infertilityrelated stress in couples $(7,11,13-15)$.

Although some studies examining the infertility stress have focused on couples, most of the studies were indicative of the higher mean score of infertilityrelated stress in women than that in men $(9,11,16,17)$. Moreover, the women who are seeking treatment are subjected to depression and anxiety more than men $(9,18)$. Furthermore, infertility-related stress has been known as the most prevalent reason for discontinuation of the treatment by couples before reaching the goal of pregnancy (19). In addition, in couples who have higher levels of stress, pregnancy is accompanied by poor outcomes (20-22).

Infertility is not only a medical issue that can affect people and their marriages but also a psychological crisis. Although some studies have shown that women are more severely affected by psychological issues caused by infertility, the investigation of couples as a unit is also of

Received 31 January 2018, Accepted 18 March 2018, Available online 3 May 2018

${ }^{1}$ Student Research Committee, School of Nursing and Midwifery, Shahid Beheshti University of Medical Sciences, Tehran, Iran. ${ }^{2}$ Midwifery and Reproductive Health Research Center, Department of Midwifery and Reproductive Health, School of Nursing and Midwifery, Shahid Beheshti University of Medical Sciences, Tehran, Iran. ${ }^{3}$ Department of Psychology, Islamic Azad University, Roodehen Branch, Tehran, Iran ${ }^{4}$ School of Nursing and Midwifery, Shahid Beheshti University of Medical Sciences, Tehran, Iran. ${ }^{5}$ Mahdiyeh Hospital, Shahid Beheshti University of Medical Sciences, Tehran.

*Corresponding Author: Giti Ozgoli, Tel: +98-021-88202012, Email: gozgoli@gmail.com 
great importance (17). Given the fact that infertility might lead to psychological issues in couples, we simultaneously investigated men and their wives. There are limited studies examining the infertility-related stress since the investigation of this issue bears some limitations. In addition, previous studies have reported inconsistent findings in this regard. With this background in mind, the present study aimed to compare infertility-related stress among the infertile couples and its relationship with infertility factors.

\section{Materials and Methods}

This cross-sectional study was performed on 150 infertile couples (300 individuals) visiting infertility centers of Tehran from October 2016 to March 2017. The sample size was estimated to be 132 couples. However, 150 couples were selected due to the possibility of drop out.

The subjects were selected through convenience sampling technique. The researchers referred to the intended centers and selected the infertile couples according to the inclusion criteria. After explaining the objectives of the study, written informed consent was obtained from all the participants. Subsequently, the volunteers were provided with the questionnaires to answer.

The criteria for inclusion were as follows: primary infertility, Iranian nationality, literacy, lack of known psychological disorders, consent to participate, and no experience of stressful events (e.g., death of close relatives or job loss within the past 6 months).

The data were collected through demographic and infertility characteristics form and Fertility Problem Inventory (FPI). The demographic and infertility characteristics form was prepared by one of the researchers and enquired some information about couples' age, education, job, economic status, residential status, age at marriage, duration of marriage, treatment failure history, duration of infertility, and reason for infertility.

Additionally, FPI was used to measure the infertilityrelated stress. This questionnaire was designed in 1999 by Newton et al at London Health Sciences Center. This inventory covers the experience of infertility-related stress in five dimensions, including social concern, sexual concern, relationship concern, need for parenthood, and childless lifestyle. The FPI consists of 46 items rated on a 6-point Likert scale (ranging from strongly disagree to strongly agree). A higher score in this inventory is indicative of greater stress (23).

Newton et al confirmed the validity of the questionnaire and its subscales using factor analysis. In addition, the reliability of this instrument was evaluated and Cronbach's alpha coefficients were $0.87,0.77,0.82,0.8,0.84$, and 0.93 for social concern, sexual concern, relationship concern, childless lifestyle, need for parenthood, and the questionnaire as a whole, respectively (23).

Similarly, Samani et al investigated the reliability and validity of this instrument in Iran. They reported the Cronbach's alpha coefficients of $0.91,0.79,0.86,0.95,0.83$, and 0.86 for social concern, sexual concern, relationship concern, childless lifestyle, need for parenthood, and the whole questionnaire, respectively. In addition, they also confirmed the validity of this instrument through factor analysis (24).

\section{Statistical Analysis}

The data were analyzed using both descriptive statistics (i.e., frequency, mean, and standard deviation) and inferential statistics (i.e., paired samples $t$ test, independent $t$ test, ANOVA, and linear regression) by the SPSS software version 18.0. Finally, $P$ values less than 0.05 were considered statistically significant.

\section{Results}

According to the results, the mean ages of males and females were $39.9 \pm 5.4$ and $31.0 \pm 5.4$ years, respectively. Out of 150 participants, $67.3 \%$ of the men and $48 \%$ of the women were within the age range of 30-40 years. Furthermore, $36 \%$ and $47 \%$ of the men and women, respectively, had an academic education. Additionally, $68 \%$ of the couples lived in Tehran, and $72 \%$ of them had an average economic status. Marriage duration was less than 5 years in $52 \%$ of the couples. Moreover, infertility duration was less than 5 years in $72.7 \%$ of the couples, and $45 \%$ of them had experienced treatment failure before. The cause of infertility was unknown in $34 \%$ of the couples.

The normality of data was evaluated through Kolmogorov-Smirnov test, and the parametric tests were used in case of normal distribution. In the comparative investigation of mean scores of infertility-related stress and its subscales between males and females, the results of paired-samples $t$ test revealed significant differences. The mean stress score was significantly higher in women than in men $(P=0.007)$. Furthermore, the comparison of the questionnaire subscales demonstrated a statistically significant difference between the mean scores of males and females regarding the social concern and need for parenthood ( $P=0.005$ and $P<0.001$, respectively).

In addition, the mean score of social concern was higher in women than in men $(30.3 \pm 7.8)$ (Table 1$)$. In addition, the mean score of social concern $(30.3 \pm 7.8)$ and need for parenthood $(40.6 \pm 8.4)$ was higher in women than in men (Table 1).

Moreover, the results of the independent samples $t$-test indicated that the mean stress score of the women was significantly higher than that of the men in the group that had treatment failure $(P=0.01)$ (Table 2$)$. The one-way ANOVA test was used to compare the mean of total stress scores between men and women in terms of different causes of infertility, and the results were indicative of no significant difference in this regard (Table 3 ).

Additionally, the results of the linear regression test revealed no significant relationship between infertility- 
Table 1. Comparison of the Total and Subscale Scores of InfertilityRelated Stress in Infertile Couples

\begin{tabular}{|c|c|c|c|}
\hline \multirow[t]{2}{*}{ Variable } & $\begin{array}{c}\text { Male } \\
(n=150)\end{array}$ & $\begin{array}{l}\text { Female } \\
(n=150)\end{array}$ & \multirow[t]{2}{*}{$P$ value } \\
\hline & \multicolumn{2}{|c|}{ Mean $\pm S D$} & \\
\hline $\begin{array}{l}\text { Total score of infertility-related } \\
\text { stress }\end{array}$ & $42.1 \pm 12.4$ & $44.8 \pm 12.0$ & 0.007 \\
\hline \multicolumn{4}{|l|}{ Subscales } \\
\hline Social concern & $28.3 \pm 8.3$ & $30.3 \pm 7.8$ & 0.005 \\
\hline Sexual concern & $21.4 \pm 7.3$ & $21.9 \pm 6.7$ & 0.4 \\
\hline Communication concern & $29.5 \pm 6.7$ & $29.5 \pm 7.1$ & 0.9 \\
\hline Childless lifestyle & $26.0 \pm 5.7$ & $26.6 \pm 6.3$ & 0.2 \\
\hline Need for parenthood & $37.6 \pm 8.5$ & $40.6 \pm 8.4$ & $<0.001$ \\
\hline
\end{tabular}

Table 2. Comparison of the Mean Scores of Infertility-related Stress Between Males and Females with and Without a History of Treatment Failure

\begin{tabular}{lccc}
\hline \multirow{2}{*}{ Variable } & \multicolumn{2}{c}{ History of Treatment failure } & \\
\cline { 2 - 2 } & \multicolumn{2}{c}{ Yes } & No \\
\cline { 2 - 2 } Value \\
\cline { 2 - 2 } $\begin{array}{l}\text { Total score of infertility- } \\
\text { related stress in men }\end{array}$ & $43.8 \pm 13.8$ & $40.7 \pm 11.0$ & 0.1 \\
$\begin{array}{l}\text { Total score of infertility- } \\
\text { related stress in women }\end{array}$ & $47.3 \pm 11.3$ & $42.7 \pm 12.2$ & 0.001 \\
\hline
\end{tabular}

related stress and infertility duration. Although this relationship was not statistically significant, the findings indicated that for each one-year increase in infertility duration, the mean score of stress increased by 0.005 in women and decreased by 0.044 in men (Table 4 ).

\section{Discussion}

Reproduction is one of the natural and vital goals of human beings for the survival of any society, which can lead to a psychological crisis when faced with problems (25). The purpose of the present study was to compare the infertility-related stress between males and females and assess its relationship with various infertility factors. The findings indicated that women had a higher mean score of infertility-related stress than men, which is in line with the results reported by El Kissi et al (26) and Gourounti et al (27). These studies emphasized that women reacted to infertility with anxiety, stress, depression, and sorrow. One of the most important causes of stress in infertile women is the fear of divorce. These women are more vulnerable to domestic violence because of infertility (28). The most important reasons behind the women's stress regarding the infertility are the thought of losing their capability to become a mother as well as concern for the continuity of their generation (17). Furthermore, being a mother has been known as the most important role of the women; therefore, the inability to attain this important goal causes higher stress in women.

In addition, even when infertility is due to male factors, most of the infertility tests and treatments are carried out on women. As a result, they are subjected to side effects of the medications and are also under much more psychological pressures compared to men $(29,30)$. The infertile women who participated in this study belonged to a society in which having a child was of great importance for a family in order to look complete. Consequently, it seems logical that these women experience higher levels of stress.

The findings of the present study also demonstrated that women had higher mean stress scores in terms of social concern and need for parenthood than men. These results are consistent with those obtained by Karaca et al, concluding that a child is considered to be the offspring of a marriage, and it has always been stated as a social expectation (17). The attitude of family members, social interactions with others and community expectations are the most important factors that can affect perceived stress in infertile couples (31). It seems that in the current study, these expectations were more highlighted due to the couples' inability to get pregnant. Moreover, considering the fact that the role of motherhood is particularly for women, they are exposed to more social expectations compared to men in this regard. Therefore, the fear of social stigma would lead to greater social concern in women.

According to the results of the present study, the women who had experienced treatment failure had higher stress scores, which could be attributed to the disappointment,

Table 3. Comparison of the Mean Scores of Infertility-related Stress Based on the Cause of Infertility Between Males and Females

\begin{tabular}{|c|c|c|c|c|c|}
\hline \multirow{3}{*}{ Variable } & \multicolumn{4}{|c|}{ Cause of Infertility } & \multirow{3}{*}{$P$ Value } \\
\hline & Male & Female & Mixed & Unknown & \\
\hline & \multicolumn{4}{|c|}{ Mean $\pm S D$} & \\
\hline Total score of infertility-related stress in men & $44.3 \pm 11.5$ & $44.4 \pm 14.1$ & $44.1 \pm 13.8$ & $38.3 \pm 10.8$ & 0.06 \\
\hline Total score of infertility-related stress in women & $44.3 \pm 10.7$ & $46.8 \pm 14.5$ & $48.2 \pm 13.4$ & $41.9 \pm 10.4$ & 0.08 \\
\hline
\end{tabular}

Table 4. Association Between the Infertility-related Stress and the Duration of Infertility in Couples

\begin{tabular}{lccc}
\hline Variable & B & Beta & 95.0\% Confidence Interval \\
\hline Infertility duration & & & \\
Male & -0.169 & -0.044 & $-0.787-0.449$ \\
Female & 0.020 & 0.005 & $-0.577-0.617$ \\
\hline
\end{tabular}


economic issues, and side effects of the drug. This is in line with the findings reported by Boivin et al (13), Lee et al (18), Coughlan et al (32), Hajiyan et al (33) and Maroufizadeh et al (34). In these studies, it has been pointed out that when the couples, especially the women, experience frequent treatment failures, the level of stress would increase in response to the examination methods and the ensuing treatments. The failure to achieve the desired goal is one of the causes of anxiety and stress. Achieving pregnancy is a valuable goal. Accordingly, infertile women with a history of failure are disappointed with this goal and therefore become more stressed.

In the present study, despite the lack of a significant relationship between stress and infertility duration, the level of stress increased among the women as the duration of infertility got longer. This finding supports the results of the studies by Ogawa et al (15), Lykeridou et al (35), Maroufizadeh et al (34) and Dadfar et al (36). Nonetheless, it is inconsistent with the findings of a study conducted by Hashemieh et al in 2013 (7). This can be due to the women's disappointment of getting pregnant and concern for getting older, which might lead to a decreased possibility of getting pregnant.

The strengths of the current study were the simultaneous investigation of the couples, utilization of the standard instrument to measure the infertility-related stress, assessment of infertility factors, and presence of couples with primary infertility. The questionnaire used in this study to assess the stress is a multidimensional reliable and valid tool that can measure infertility-specific stress. This tool measures aspects such as sexual concern, social concern, communication concern and childless lifestyle (24). Due to such features, the use of this tool in this research is one of its strengths. Moreover, the evaluation of couples is another strength of this study because in most studies only infertile women have been studied (37). On the other hand, the limitations of this study included the cross-sectional design of the study, limited number of centers for sample selection, and possibility of dishonest responses to the questionnaire by the participants.

\section{Conclusions}

As the findings of the present study revealed, the infertile women had higher stress compared to the infertile men. In addition, a history of treatment failure could increase the infertility-related stress in women. Similarly, the increase in the duration of infertility was accompanied by augmented stress in women. There was a reciprocal relationship between stress and fertility. Moreover, the infertile women were more vulnerable to infertilityrelated stress compared to men, which might be due to receiving treatments and experiencing probable failures. Consequently, it is recommended that women who have experienced treatment failure be provided with proper psychological care and evaluations using reliable screening tests before the initiation of therapeutic activities.

\section{Conflict of Interests}

Authors declare that they have no conflict of interests.

\section{Ethical Issues}

Written informed consent was obtained from all the participants. The current study was approved on 18/7/2016 by the Ethics Committee of Shahid Beheshti University of Medical Sciences, Tehran, Iran (code: IR.SBMU. PHNM.1395.500).

\section{Financial Support}

None.

\section{Acknowledgments}

The current study was derived from a $\mathrm{PhD}$ thesis submitted by the first author. The authors of this study sincerely appreciate the cooperation of the Midwifery and Nursing Faculty of Shahid Beheshti University of Medical Sciences and the staff of infertility centers of Ayatollah Taleghani and Mahdieh hospitals in Tehran. We would also like to extend our gratitude to the couples who participated in this study. This study received no specific grant from any funding agency.

\section{References}

1. Sehhatie Shafaie F, Mirghafourvand M, Rahimi M. Perceived stress and its social-individual predicors among infertile couples referring to infertility center of Alzahra hospital in Tabriz in 2013. International Journal of Women's Health and Reproduction Sciences. 2014;2(5):291-296. doi:10.15296/ijwhr.2014.47

2. Najafi M, Soleimani AA, Ahmadi K, Javidi N, Hoseini Kamkar E. The effectiveness of emotionally focused therapy on enhancing marital adjustment and quality of life among infertile couples with marital conflicts. Int J Fertil Steril. 2015;9(2):238-246. doi:10.22074/ ijfs.2015.4245

3. Rahimi Ahmadabadi S, Hejazi A, Attaran $\mathrm{H}$, Aghamohammadian Sharbaf H, Karashki H, Kohestani L. Comparision of parenting styles \& mental health of infertile couples seeking adoption by childless couples. Iranian Journal of Forensic Medicine. 2014;21(3):157166.

4. Tamannaifar MR. A comparative study of mental health, marital adjustment and coping responses among fertileinfertile women. Clinical Psychology \& Personality. 2011;3(4):51-60.

5. Sheikhan Z, Ozgoli G, Azar M, Alavimajd H. Domestic violence in Iranian infertile women. Med J Islam Repub Iran. 2014;28:152.

6. Zivaridelavar M, Kazemi A, Kheirabadi GR. The effect of assisted reproduction treatment on mental health in fertile women. J Educ Health Promot. 2016;5:9. doi:10.4103/2277-9531.184552

7. Hashemieh C, Neisani Samani L, Taghinejad H. Assessment of anxiety in pregnancy following assisted reproductive technology (ART) and associated infertility factors in women commencing treatment. Iran Red 
Crescent Med J. 2013;15(12):e14465. doi:10.5812/ ircmj. 14465

8. Golestan Jahromi M, Mosalanejad L, Ghavi F. Psychological distress in infertile and fertile women. International Journal of Analytical, Pharmaceutical and Biomedical Sciences. 2015;4(7):60-69.

9. Klemetti R, Raitanen J, Sihvo S, Saarni S, Koponen P. Infertility, mental disorders and well-being--a nationwide survey. Acta Obstet Gynecol Scand. 2010;89(5):677-682. doi:10.3109/00016341003623746

10. Luk BH, Loke AY. The impact of infertility on the psychological well-being, marital relationships, sexual relationships, and quality of life of couples: A systematic review. J Sex Marital Ther. 2015;41(6):610-625. doi:10.10 80/0092623x.2014.958789

11. Patel A, Sharma PS, Narayan P, Binu VS, Dinesh N, Pai PJ. Prevalence and predictors of infertility-specific stress in women diagnosed with primary infertility: A clinic-based study. J Hum Reprod Sci. 2016;9(1):28-34. doi:10.4103/0974-1208.178630

12. Agostini F, Monti F, De Pascalis L, Paterlini M, La Sala GB, Blickstein I. Psychosocial support for infertile couples during assisted reproductive technology treatment. Fertil Steril. 2011;95(2):707-710. doi:10.1016/j. fertnstert.2010.06.011

13. Boivin J, Griffiths E, Venetis CA. Emotional distress in infertile women and failure of assisted reproductive technologies: meta-analysis of prospective psychosocial studies. BMJ. 2011;342:d223. doi:10.1136/bmj.d223

14. Lancastle D, Boivin J. A feasibility study of a brief coping intervention (PRCI) for the waiting period before a pregnancy test during fertility treatment. Hum Reprod. 2008;23(10):2299-2307. doi:10.1093/humrep/den257

15. Ogawa M, Takamatsu K, Horiguchi F. Evaluation of factors associated with the anxiety and depression of female infertility patients. Biopsychosoc Med. 2011;5(1):15. doi:10.1186/1751-0759-5-15

16. Casu G, Gremigni P. Screening for infertility-related stress at the time of initial infertility consultation: psychometric properties of a brief measure. J Adv Nurs. 2016;72(3):693-706. doi:10.1111/jan.12830

17. Karaca A, Unsal G. Psychosocial problems and coping strategies among Turkish women with infertility. Asian Nurs Res (Korean Soc Nurs Sci). 2015;9(3):243-250. doi:10.1016/j.anr.2015.04.007

18. Lee SH, Wang SC, Kuo CP, Kuo PC, Lee MS, Lee MC. Grief responses and coping strategies among infertile women after failed in vitro fertilization treatment. Scand J Caring Sci. 2010;24(3):507-513. doi:10.1111/j.14716712.2009.00742.x

19. Anderson K, Nisenblat V, Norman R. Lifestyle factors in people seeking infertility treatment - A review. Aust N Z J Obstet Gynaecol. 2010;50(1):8-20. doi:10.1111/j.1479828X.2009.01119.x

20. Brandes M, van der Steen JO, Bokdam SB, et al. When and why do subfertile couples discontinue their fertility care? A longitudinal cohort study in a secondary care subfertility population. Hum Reprod. 2009;24(12):31273135. doi:10.1093/humrep/dep340
21. Matthiesen SM, Frederiksen Y, Ingerslev HJ, Zachariae R. Stress, distress and outcome of assisted reproductive technology (ART): a meta-analysis. Hum Reprod. 2011;26(10):2763-2776. doi:10.1093/humrep/der246

22. Zhou F, Dong Y. Psychological stress is related to treatment outcome in women undergoing in-vitro fertilization and Embryo transplantation. Int J Clin Exp Med. 2016;9(4):7481-7488.

23. Newton CR, Sherrard W, Glavac I. The Fertility Problem Inventory: measuring perceived infertility-related stress. Fertil Steril. 1999;72(1):54-62. doi:10.1016/S00150282(99)00164-8

24. Omani Samani R, Almasi-Hashiani A, Shokri F, Maroufizadeh S, Vesali S, Sepidarkish M. Validation study of the Fertility Problem Inventory in Iranian infertile patients. Middle East Fertil Soc J. 2017;22(1):4853. doi:10.1016/j.mefs.2016.07.002

25. Karimzadeh M, Salsabili N, Akbari Asbagh F, Teymouri R, Pourmand G, Soleimanieh Naeini T. Psychological Disorders among Iranian Infertile Couples Undergoing Assisted Reproductive Technology (ART). Iran J Public Health. 2017;46(3):333-341.

26. El Kissi Y, Romdhane AB, Hidar S, et al. General psychopathology, anxiety, depression and self-esteem in couples undergoing infertility treatment: a comparative study between men and women. Eur J Obstet Gynecol Reprod Biol. 2013;167(2):185-189. doi:10.1016/j. ejogrb.2012.12.014

27. Gourounti K, Lykeridou K, Vaslamatzis G. Increased anxiety and depression in Greek infertile women results from feelings of marital stress and poor marital communication. Health Science Journal. 2012;6(1):6981.

28. Yildizhan R, Adali E, Kolusari A, Kurdoglu M, Yildizhan B, Sahin G. Domestic violence against infertile women in a Turkish setting. Int J Gynaecol Obstet. 2009;104(2):110112. doi:10.1016/j.ijgo.2008.10.007

29. Baghianimoghadam $\mathrm{MH}$, Aminian $\mathrm{AH}$, Baghianimoghadam B, et al. Mental health status of infertile couples based on treatment outcome. Iran J Reprod Med. 2013;11(6):503-510.

30. Munoz D, Kirchner T, Forns M, Penarrubia J, Balasch J. Infertility related stressors in couples initiating in vitro fertilization (IVF). Annuary of Clinical and Health Psychology. 2009;5:95-101.

31. Wang JY, Li YS, Chen JD, et al. Investigating the relationships among stressors, stress level, and mental symptoms for infertile patients: A structural equation modeling approach. PLoS One. 2015;10(10):e0140581. doi:10.1371/journal.pone.0140581

32. Coughlan C, Walters S, Ledger W, Li TC. A comparison of psychological stress among women with and without reproductive failure. Int J Gynaecol Obstet. 2014;124(2):143-147. doi:10.1016/j.ijgo.2013.08.006

33. Hajiyan T, Afshari P, Abedi MR, Hashemi E. Investigating Infertility-Related Stress and Adoption in Iranian Infertile Females with Assisted Reproductive Technology Failure. Jundishapur J Chronic Dis Care. 2017;6(2):1-6. doi: $10.5812 /$ jjcdc.39632 
34. Maroufizadeh S, Karimi E, Vesali S, Omani Samani R. Anxiety and depression after failure of assisted reproductive treatment among patients experiencing infertility. Int J Gynaecol Obstet. 2015;130(3):253-256. doi:10.1016/j.ijgo.2015.03.044

35. Lykeridou K, Gourounti K, Deltsidou A, Loutradis D, Vaslamatzis G. The impact of infertility diagnosis on psychological status of women undergoing fertility treatment. J Reprod Infant Psychol. 2009;27(3):223-237. doi:10.1080/02646830802350864
36. Dadfar F, Dadfar M, Kolivand PH. Comparison of Frequency and Intensity of Stressors in Infertile Couples Undergoing Intrauterine Insemination Treatment, IntraCytoplasmic Sperm Injection Treatment and without Treatment. The Neuroscience Journal of Shefaye Khatam. 2015;4(1):26-36. doi:10.18869/acadpub.shefa.4.1.26

37. Yilmaz T, Oskay UY. The Evaluation of Methods Used to Cope with Infertility Stress of Infertile Couples in Turkey. Int J Caring Sci. 2017;10(3):1595-1604.

(C) 2019 The Author (s); This is an open-access article distributed under the terms of the Creative Commons Attribution License (http://creativecommons.org/licenses/by/4.0), which permits unrestricted use, distribution, and reproduction in any medium, provided the original work is properly cited. 